\title{
Did the Intergenerational Solidarity Pact increase the employment rate of older workers in Belgium? A macro-econometric evaluation
}

\author{
Muriel Dejemeppe ${ }^{1}$, Catherine Smith ${ }^{1}$ and Bruno Van der Linden 1,2,3*
}

\author{
*Correspondence: \\ bruno.vanderlinden@uclouvain.be \\ ${ }^{1}$ IRES - Université catholique de \\ Louvain, Louvain-la-Neuve, Belgium \\ ${ }^{2}$ Fonds de la Recherche \\ Scientifique-FNRS, Brussels, Belgium \\ Full list of author information is \\ available at the end of the article
}

\begin{abstract}
In December 2005, the Belgian government adopted the law on the Intergenerational Solidarity Pact (ISP) aimed at increasing the employment rate of older workers. The main policies of the ISP consist of a pension bonus, reductions in employers' social security contributions and measures discouraging early retirement while encouraging working time reductions at the end of the career. We aim at evaluating the overall effectiveness of the ISP in raising the employment rate of older workers. To that purpose, we compare the actual evolution of the employment rate after the implementation of the policies to its predicted (counterfactual) evolution based on the estimation of a macro-econometric model in a period prior to the ISP. The results suggest a slight positive impact of the ISP on the employment rate of older workers but to the detriment of the younger workers. However, there is a lack of statistical power to draw firm conclusions on the overall effect of the ISP.
\end{abstract}

JEL classification: J21, J26, H53, E32

Keywords: Aging; Evaluation of labor market policies; Macro-econometrics

\section{Introduction}

The challenge brought by an aging population on the welfare system of many countries in the world is a well-known fact. In this respect, Belgium is particularly exposed because of policies introduced between the 70's and the 90's fostering early exit from the labor market. According to OECD statistics for 2005, in Belgium, the employment rate of men and women aged 55 to 59 years old was, respectively, $55.4 \%$ and $31.8 \%$, while they were $67.2 \%$ and $48.6 \%$, on average, in the EU15. In 2012, the situation has improved with an employment rate of $63.9 \%$ and $48.4 \%$ for elderly men and women in Belgium compared to $73.2 \%$ and $59.4 \%$, on average, in the EU15 countries.

Under the impulse of the Lisbon strategy, Belgian policy-makers began to acknowledge the issue of population aging and adopted a package of active aging policies on December 2005, called the law on the Intergenerational Solidarity Pact (Pacte de Solidarité entre les Générations), despite the strong opposition of labor unions. The objective of the Intergenerational Solidarity Pact (ISP) was to increase the employment rate of older workers. The main policies consist in a reduction in employers' social security contributions, several reforms intending to discourage access to early retirement, an easier access to working

(c) 2015 Dejemeppe et al. Open Access This article is distributed under the terms of the Creative Commons Attribution 4.0 International License (http://creativecommons.org/licenses/by/4.0/), which permits unrestricted use, distribution, and reproduction in any medium, provided you give appropriate credit to the original author(s) and the source, provide a link to the Creative Commons license, and indicate if changes were made. 
time reduction with (partial) wage compensation, and a pension bonus. In 2008, the reduction in employers' social security contributions represented, on average, $0.7 \%$ of total labor cost among workers aged 50 years old and over. The pension bonus amounted to 2 euros per day of full-time work while being at least 62 years old and up to the legal retirement age of 65 years old. ${ }^{1}$

The aim of our analysis is to evaluate the overall effect of the ISP on the official target of the program, namely the (headcount) employment rate of older workers by gender: did the ISP have any major impact on their employment rate compared to a non-ISP counterfactual? We also aim at evaluating whether the employment rate of a younger age group has been indirectly affected by the ISP through negative or positive spillover effects. The evaluation period ends in 2008q2 since, as of this moment, the effects of the ISP policies cannot be disentangled from the policies taken to counteract the effect of the financial and economic crisis.

This paper relies on a macro-econometric evaluation to assess the impact of the ISP policies taken as a whole. Although crucial for policy-making, an assessment of the macro-economic impact of the ISP reform has never been rigorously conducted for Belgium, that is, in searching for a causal link between the ISP and the increasing employment rate among older people from 2007 onwards. How can then citizens be ensured that public funds are spent wisely? Furthermore, most of the evaluation literature on labor market policies takes a micro-econometric approach, focusing on the evaluation of a specific program on its direct (and, at times, indirect) beneficiaries. The drawback of relying only on this approach is that it fails to capture possible general equilibrium impacts. And these impacts are likely to be further amplified if the program is part of a larger set of reforms, as is the case with the ISP.

Our evaluation method consists in comparing the actual quarterly evolution of the age and gender-specific employment rates over the period 2007 to mid-2008 to a counterfactual evolution. The latter should measure what would have happened in the absence of the ISP. It is constructed by first estimating a macro-econometric model explaining the quarterly age and gender-specific employment rates over the period 1997 (first year where the data are available) to 2007. Next, this estimated model is used to forecast the employment rate from 2007 onwards. A positive difference between the actual value of the employment rate and the predicted, counterfactual value is then interpreted as a positive impact of the ISP.

A widely-used major determinant of the employment rate is the current and past levels of real GDP. For the forecasts, we assume that the observed level of GDP is the same whether the ISP is in place or not. As this assumption might be questioned, so we check the robustness of our results by considering instead the GDP of the neighboring countries of Belgium. Some other determinants of headcount employment are found in the macroeconometric literature, namely the cost of labor, working hours and labor productivity (Bodart et al. 2009; Mourre 2006). As the forecast has to generate a convincing counterfactual, we cannot consider the cost of labor nor working hours of the older workers in the model specification simply because the ISP is affecting these variables to an extent that can hardly be predicted without a structural model of wages and hours worked. Building such a model is clearly beyond the scope of this paper. Next, determinants of the employment rate other than the ISP could in principle have changed during that period. However, we have found no important shock other than the ISP that could have had a 
major influence on the employment rate of the older workers at that time. Our empirical analysis cannot reject the hypothesis that the ISP had no effect on the employment rate of the salaried workers aged 50 or more and occupied in the private sector.

A similar evaluation method was used by Kopits (1978) to assess the employment effect of a temporary wage subsidy in France (incentive bonus for job creation) for the period 1959-1975. The author estimates an employment equation by industry for the period before the subsidy was made available. Then, employment is predicted over two quarters and the difference between the actual values and the forecasts are used to evaluate the impact of the wage subsidy. More recently, Dmitrijeva and Hazans (2007), Fahr and Sunde (2009), Hertweck and Sigrist (2013) and Klinger and Rothe (2012) evaluate the macro effect of the Hartz I/II and III reforms in Germany on the efficiency of the matching process between job seekers and vacancies. To that purpose, they estimate a matching function on their entire period of observation and make the matching efficiency dependent on a constant term, a business cycle indicator (the IFO business expectations index), month fixed effects and a (treatment) dummy equal to 1 after the implementation of the Harz reforms. This treatment dummy is not made time dependent, thus allowing only for a single structural change of the outcome variable. Given the usual lags associated with the implementation of policies and the response of the various parties involved, labor market reforms are expected to have an impact only after some time has passed. This justifies time-varying treatment effects as we do in the present paper. Besides, our evaluation approach, which consists in comparing actual outcomes to predicted ones, is less parametric and more flexible than estimating treatment effects within a regression model.

Another method that was commonly used in the 90's to evaluate macro impacts of labor market policies uses variations in program scale (spending or number of participants) over time and/or across regional units or countries (Calmfors and Skedinger 1995; de Koning 1993; Hujer et al. 2002; Jackman et al. 1990; Layard et al. 1991; Lehmann 1993; OECD 2011). The fundamental issue of this evaluation approach is to ensure that these variations are exogenous and, if they are not, to rely on credible instruments. For the evaluation of the ISP, this type of method cannot be envisaged in any case because of the high number of policies introduced by the ISP and data limitation.

To the best of our knowledge, for Belgium, there is only one paper, Bassilière et al. (2007), that investigates the macro impact of one policy of the ISP, which is the reduction in employers' social security contributions (henceforth, "RESSC") for older workers. Bassilière et al. (2007) use simulations of a large annual macro-econometric model with and without the reduction and then compare the two scenarios. They find a positive impact on the employment of the older workers but a negative impact on the employment of younger workers with low wages. It goes without saying that these results strongly depend on the underlying assumptions of the simulated model. Turning to micro-econometric analyses, Albanese and Cockx (2015) evaluate RESSC introduced in 2002 and targeted at workers older than 58 . They find positive but non-significant effects on their employment rate. This effect is however more important and significant for workers employed in sectors with a high incidence of early retirement. Lefevre and Orsini (2011) and López-Novella (2012) conclude that the pension bonus had, if any, a very limited effect on the employment rate of male old workers.

This paper proceeds by explaining, in section 2 , the institutional setting, the main features of the ISP and its expected effects on the employment rate of older workers. Section 
3 describes the data. In section 4, we explain the method used to evaluate the overall impact of the ISP on the age and gender-specific employment rates in Belgium. In section 5 , the results are presented and interpreted. The final section concludes.

\section{Institutional setting, the ISP law and its expected effects}

This section is divided in two parts. The first one provides a brief description of the organization of the social security and pension systems in Belgium. The second one is devoted to the description of the main policies implemented through the ISP and to the discussion of their expected effects.

\subsection{Institutional background around the reform of the ISP}

Belgium is a federal state that has decentralized some policies to regional authorities (Brussels, Flanders and Wallonia). The social security and pension systems are organized at the federal level. The payment of unemployment benefits (UB) and the issuing of sanctions in the case of non-compliance with the rules are federal competencies organized by the National Office for Employment (ONEM). The regions, in turn, are responsible for the Public Employment Services, which are in charge of counseling, job search assistance, intermediation services and training of unemployed and employed workers. The policies of the ISP were taken at the federal level.

Belgium has a pay-as-you-go public pension system. All employees and self-employed people pay compulsory contributions to the federal state funds for old age and invalidity pensions. The legal retirement age is 65 years old for men and was brought from 60 years old in 1996 to 65 years old in 2009 for women. In this setting, no minimum years of paid contributions is imposed. The basic state pension depends on the occupational status, the gross salary, the number of years worked and the family composition.

Anticipated retirement can be claimed up to 5 years before the normal retirement age with at least 35 years of paid contributions (including periods on unemployment or disability benefits). However, four other schemes allow an early withdrawal from the labor market in Belgium. Those mechanisms are described as they were before the introduction of the ISP in December 2005.

First, various schemes allowing older workers to withdraw earlier from the labor market coexist. The most important one, the collectively agreed (or "conventional") early-retirement regime, entitles old workers who loose their jobs to UB with an additional allowance paid by the previous employer. The requirement is a minimum age of 58 with at least 25 years of career. People that benefit from this early retirement scheme are exempted from job search, and pension coverage is continued during that period. The employer has to replace the early retired for a period of at least three years, although exemptions to this obligation are awarded in $57 \%$ of the cases (OECD 2003, p. 75). However, several exceptions to the age requirement exist. For instance, the age threshold can be set to 56 for night work and between 50 and 55 for firms in financial difficulties or in restructuring. Specific eligibility conditions can also be defined at the sectoral level by collective agreements. There is also an "unofficial early retirement scheme." As in the collectively agreed pre-retirement regime, the employer who lays off a worker under this scheme pays a supplement to UB. This scheme is however more flexible for the employer since there are no specific requirements to fulfill apart from the fact that the worker is at least 45 years old. The conditions of the 
early retirement (such as the minimal notice period, the amount and duration of the lump-side payment) are defined by a private agreement between the employer and the worker.

The second scheme is known as the regime of old aged unemployed exempted from job search (chômeur âgé non demandeur d'emploi). Older unemployed workers can be exempted from searching for a job and being available on the labor market. To benefit from these advantages, the unemployed must be either aged between 50 and 57 years old, unemployed for more than one year and have reported a very long career (at least 38 years), or aged at least 58 years old. These workers continue to be eligible for UB and receive in addition a benefit supplement.

The third scheme is the full-time time-credit (crédit temps à temps plein). People of all ages can interrupt their career for a period of one year if they have worked for the same employer for at least 12 months out of the 15 last months. The period of full-time timecredit can be extended up to 5 years by means of collective agreements at the sectoral level. People on full-time time-credit receive a lump-sum allowance from the National Office for Employment to compensate partially the loss of salary. Workers at the end of their career can then use this scheme right before being eligible for other routes toward early withdrawal. It should be mentioned that a specific scheme, the part-time timecredit, allows workers above the age of 50 and with 5 years full-time within the same firm, to reduce working time either by $20 \%$ or by $50 \%$ until the age of statutory retirement. The resulting loss of salary is partially offset by a lump-sum (generous) allowance from the National Office for Employment.

Disability benefits constitute the last scheme leading to early withdrawal. It requires that the workers are not able to work.

\subsection{The Intergenerational Solidarity Pact}

Belgium has not waited for the introduction of the Intergenerational Solidarity Pact (ISP) to try to expand the employment rate of the older workers. ${ }^{2}$ However, the ISP marks a turning point through the number of policies taken on various aspects of older workers' employability.

This sub-section presents the main new policies included in the ISP and the major changes brought to existing policies. Only policies introduced over our evaluation period (2007 to mid-2008) are considered. It begins by describing the policies and then looks at the magnitude of the policies in terms of number of participants and expenditure. The age of eligibility varies across policies. Most of time they target people aged 50 years old and over, and sometimes people aged 45 and over. This sub-section also discussed likely effects of those policies.

\subsubsection{Description}

The four main policies consist in a pension bonus, RESSC, more restrictive access to the early retirement scheme and less restrictive access to part-time time-credit.

The pension bonus was introduced in January 2007, so about one year after the adoption of the ISP law. All workers and self-employed aged at least 62 years old or with at least 44 years of paid contributions received a bonus for pensions starting from January 2007 and before 2013. The bonus corresponded to 2 euros for each day worked in a full time position, limited to 624 euros for each full year of work. 
In April 2007, within the framework of the ISP, the government introduced a specific RESSC for workers aged between 50 and 56 years old earning 12,000 euros (gross) or less per quarter. The quarterly reduction amounts to 50 euros per quarter for a worker aged 50 years old and increased by 50 euros every year until the age 56 . The reduction is permanent and concerns both the new hires and the incumbent workers. For workers aged at least 58 (respectively, 57), employers' social security contributions were already reduced by 400 euros per quarter since April 2002 (respectively, January 2004). With the ISP, the government reinforced the RESSC for workers aged 57 with a further reduction of 50 euros per year worked from 57 years old onwards. The maximum quarterly RESSC is reached at the age of 65 years and amounts to 800 euros. RESSC targeted at workers aged 50 or more represented $0.6 \%$ of the total wage cost of these workers in 2007 and $0.7 \%$ in 2008.

Since the ISP, the government has also tried to discourage access to early retirement in three ways. First, at the beginning of 2008, the age requirement of the collectively agreed pre-retirement regime increased from 58 to 60 , and the required years of career increased from 25 to 30 (26) for men (women). The age threshold remained at 58 for particularly long careers or in the case of heavy work, providing the worker has at least 35 years of career. Second, the government decided to make the unofficial early retirement scheme less attractive. Since April 2006, the allowance paid to the unemployed worker by the previous employer has been made subject to social security contributions. Thirdly, since January 2007, the employer's allowance under both the official and unofficial preretirement regime has to be paid to the old worker even if she finds a job in another firm. ${ }^{3}$ In case of refusal of the former employer, financial penalties are applied. At the same time, the government made the possibility of gradually reducing working time more appealing for the workers aged 50 or more. Since June 2007, the eligibility condition for the part-time time-credit changed to 3 , instead of 5 , years of seniority with the current employer.

On top of these four main policies, early-retired workers laid-off by restructuring firms have to remain available for work since April 2006. As of January 2008, the ISP constrained an increasing number of early-retired workers to stay available for the labor market until the age of 58 . However, on average in 2008 , only $1 \%$ of the early-retirees were available for work. Some policies of the ISP were also introduced to promote the adaptation of the workplace to older workers, but they were not widely used.

\subsubsection{Participants and expenditure}

This subsection describes and comments on the data gathered on the number of participants and the program expenditure for a number of policies targeted at older workers in Belgium during the period 2002-2008. Although the ISP law was adopted in December 2005, the graphs are for the period 2002-2008 to be able to see the changes the ISP brought to already existing policies. Figure 1 shows the evolution of real expenses and participants in the collectively agreed early retirement scheme. Both curves are on the rise during the post- 2005 period. Since there is no obligation for the worker to report the supplement to the UB under the unofficial early retirement scheme, no figure on the use of this scheme is available. As the ISP reforms affect more substantially this unofficial scheme than the collectively agreed one, the post-2005 evolution on Fig. 1 could capture a substitution between the two schemes. 


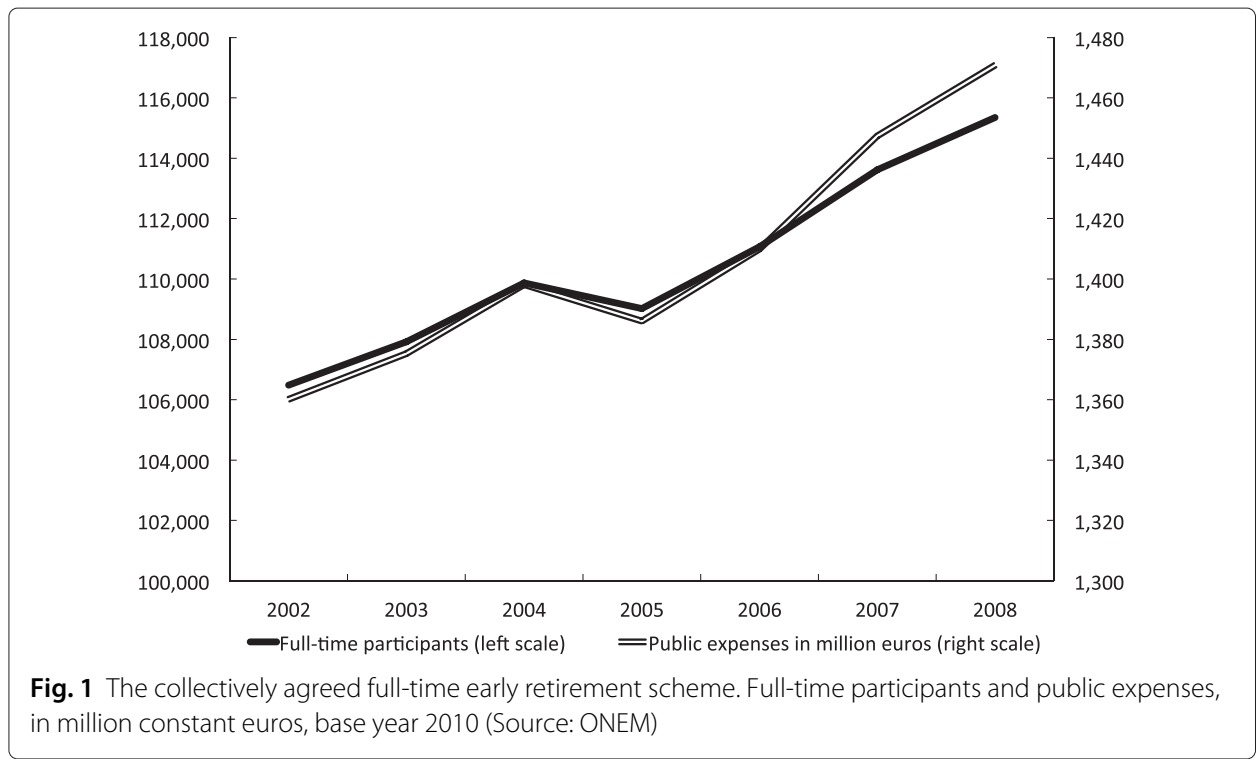

Figure 2 shows the annual number of participants aged 50 or more by measure. It reveals an increase in the number of participants benefiting from RESSC between 2003 and 2004. Most of this rise is however spurious since there are no data on the number of beneficiaries of RESSC for the period 2002-2003. ${ }^{4}$ The strongest increase in the number of participants is registered between 2006 and 2007. It is mainly due to the extension of the RESSC to people aged 50 or more within the framework of the ISP. In the year following

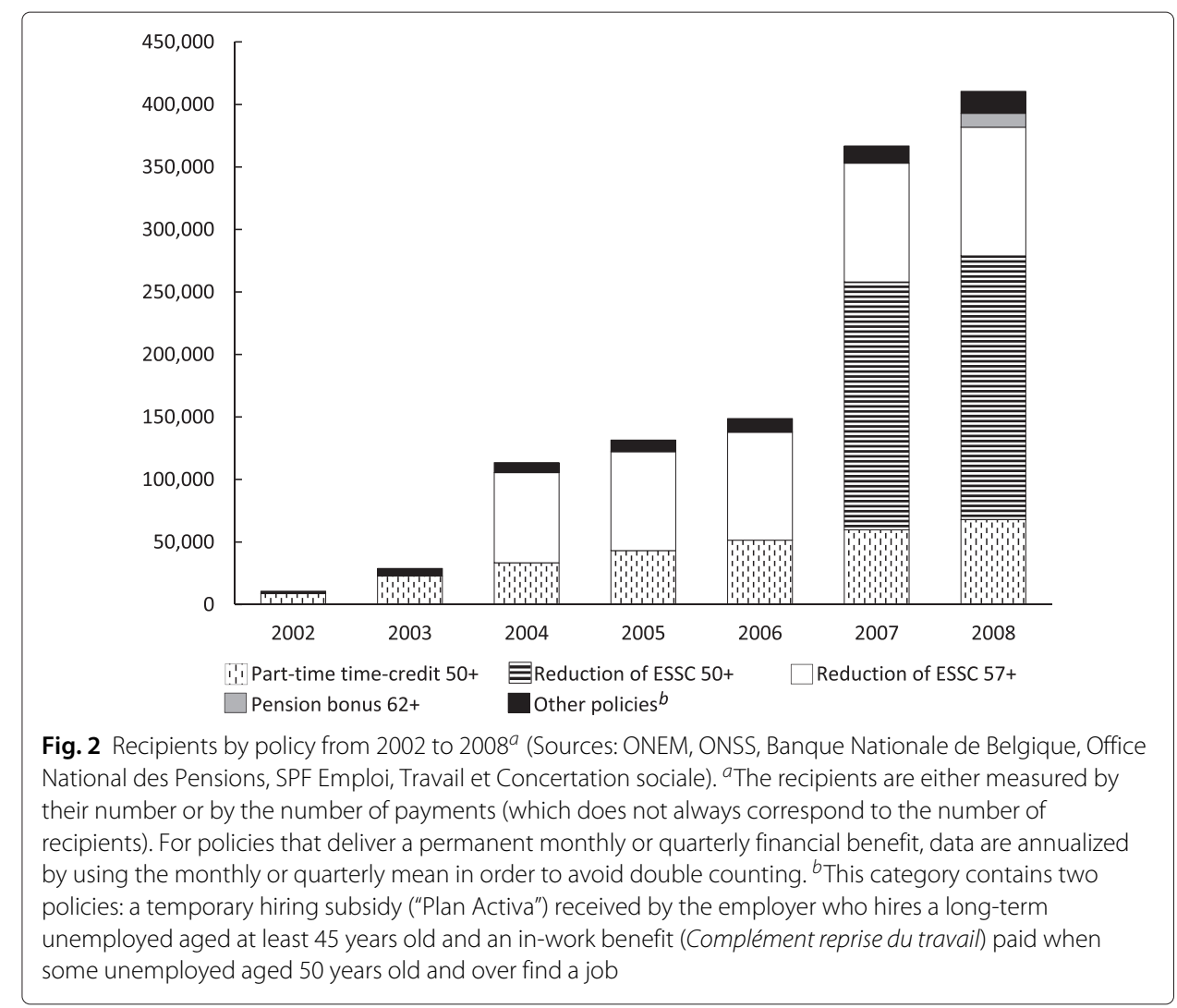




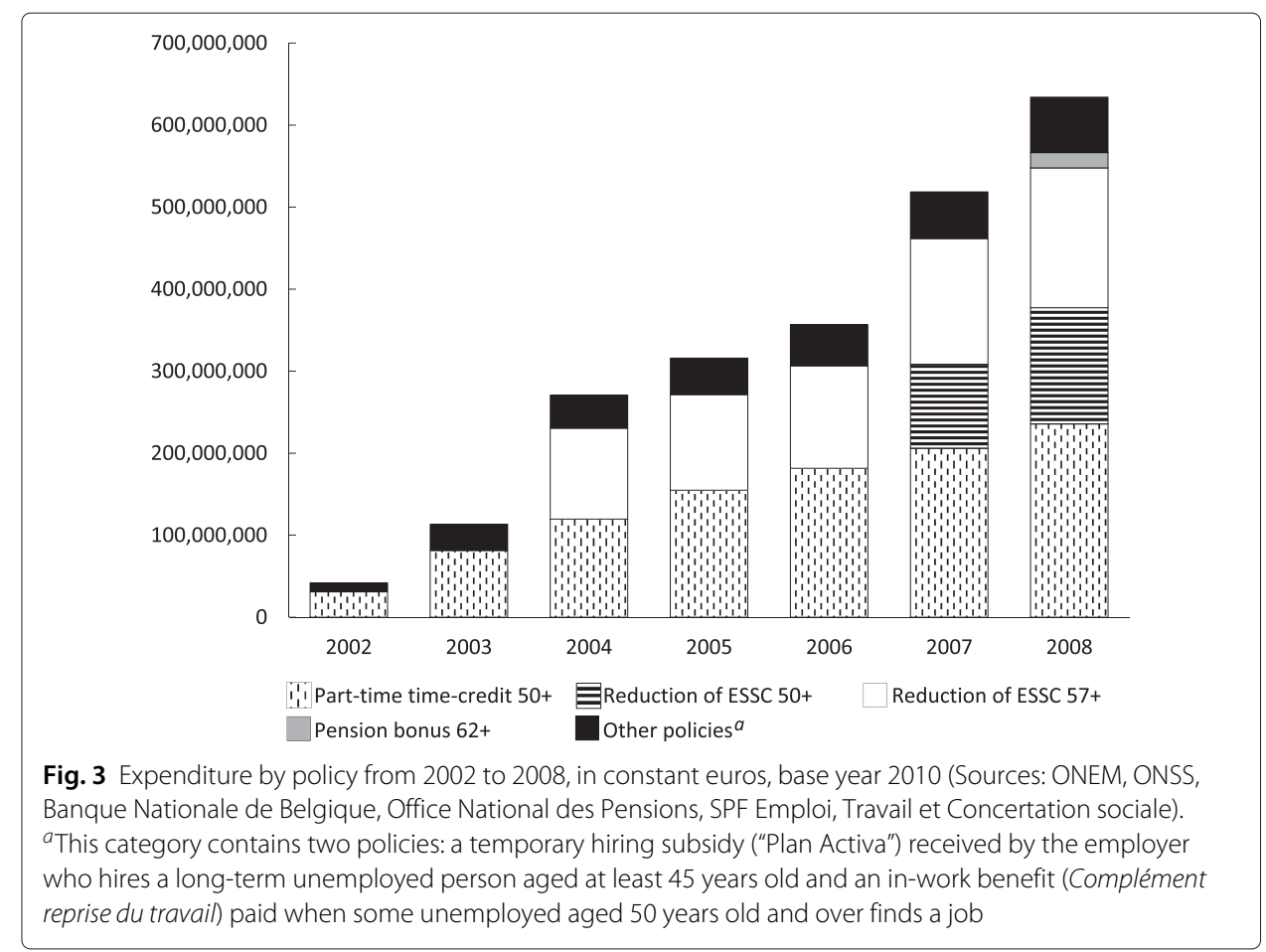

the adoption of the ISP law, the policies with the largest number of participants are the RESSC for workers aged 50-56 (198,326 recipients in 2007) and the part-time time-credit $(59,741$ mean payments per months in 2007).

Figure 3 gives the yearly public expenditure in constant euros (base year 2010) for the main policies targeted at older workers in Belgium during the period 2002-2008. The real expenditure went from 42 million euros in 2002 to 634 million in 2008. There is a rise in the expenditure between 2003 and 2004, which is spurious for the same reason as for the participants (cf. above). A sharp increase appears between 2006 and 2007 with the RESSC for workers aged 50-56 decided within the framework of the ISP.

In 2007, following the implementation of the ISP, a fundamental change was seen in the public investment for older workers, especially through the RESSC for workers aged 50-56. There is indeed a sharp rise in the number of participants and an increase in the spending at that time.

\subsubsection{Expected effects}

What are the mechanisms through which the policies of the ISP should have an impact on the employment rate of older workers? We look at potential effects in the short run. The adoption of the reform was for long uncertain because of a strong opposition of labor unions. So, economic agents could not easily anticipate the measures actually decided.

The first policy consists in a pension bonus received by people continuing to work after the age of 62. This provides an incentive to stay active before that age. From 62 onwards, the expected positive effect is to increase the opportunity cost of early retirement and induce people to work longer (Maes 2008). However, there is also an income effect working in the other direction: the bonus increases the expected income from early retirement and may push some people to retire earlier (Lefevre and Orsini 2011; Maes 2008). At the micro-level, both the difference-in-differences method used by López-Novella (2012) and 
the structural modeling approach of Lefevre and Orsini (2011) conclude that the net effect of the pension bonus is very small.

The second policy involves RESSC targeted to older workers. Belgium is a unionized economy with an estimated union coverage in the private sector of $96 \%$ (Source: ICTWSS data base). Under wage bargaining, linear tax cuts and RESSC have a favorable impact on the employment rate if the flow value in unemployment (unemployment benefits plus the value of time) is not indexed on the bargained wage (Pissarides 1998). A lump-sum RESSC increases the total surplus (or value) of a job. Under Nash bargaining, the reduction is shared between workers and firms, and the part accruing to the employers induces a rise in labor demand. In the Belgian context, in particular for older workers, such an effect may be less obvious, and here are some reasons why.

Over the period 1998-2006 in Belgium, Cataldi et al. (2012) and Vandenberghe et al. (2013) provide evidence that a rise in the share of occupied workers aged at least 50 reduces the log of firm's average value added per worker more than the log of its average labor cost per worker. So, the productivity-labor cost gap is significantly and negatively affected by the share of old workers in the firm. Unless an agreement can be found through early retirement schemes, employers are reluctant to fire these workers because of the threat of a labor dispute with the (relatively powerful) Belgian unions. ${ }^{5}$ In this context, the introduction of RESSC lowers the productivity-labor cost gap. Whether the limited reduction introduced by the ISP does more than compensate this gap is an empirical question. If it does, this reduction provides an incentive to keep old workers longer in the firm (potentially inducing a substitution effect detrimental to the employment level of younger workers).

Thirdly, we consider the potential impact of the package of reforms affecting early retirement, namely making early retirement more costly to employers (in particular in the unofficial scheme), increasing the earliest age at which early retirement can begin, and raising the minimal required career length. Since, as argued above, employers would like to reduce their old workforce but can hardly do so without the early retirement schemes, the above-mentioned combination of changes could give employers an incentive to keep part of this workforce longer. However, these changes can be seen as a piecemeal reform since the ISP did not modify simultaneously the multiple pathways to retirement. Neither disability insurance (DI) nor the anticipated retirement were reformed. Jousten et al. (2013) provides descriptive evidence that the share of women aged 55-64 on DI increased after 2007. For both genders, the take-up rate of anticipated retirement increased as well. In sum, this package of reforms affecting early retirement can contribute to an improvement in the employment rate and/or it induces substitutions among the different pathways to retirement. To illustrate these spillovers effects, consider a reform in Austria that increased the age at which anticipated retirement can be claimed. Staubli and Zweimüller (2013) show that this reform had a positive but moderate causal effect on the employment rate, a substantial positive one in the unemployment rate and a small positive effect on the percentage of people on disability benefits.

Regarding the fourth policy, allowing a reduction of working time at the end of the career and compensating (partly) the worker for the wage loss are believed to increase the employment rate of older people. Working hours are indeed not completely flexible and people cannot always reduce their working time as they would like (Gustman and Steinmeier 1983; Kahn and Lang 1995; Stewart and Swaffield 1997; Euwals 2001; Bryan 
2007; Gielen 2009). In particular, Decicca (2007) conclude for the US that the "amount by which hours being constrained is estimated to raise retirement probabilities is nearly as large as the effect of being in relatively poor health" (p. 251). A reduction of working time when getting older could also have a beneficial effect on health and hence could prolong the attachment to the labor market. However, if participation to this scheme is preparing a complete withdrawal from the labor market (as suggested by (Looy et al. 2014), for a Belgian region), this effect could be short-lived. On the demand side, the policy could have positive (improved employee satisfaction) as well as negative (signal of a reduced availability to work, organizational difficulties) effects on employment (Devisscher and Sanders 2007). Induced effects on the labor supply of other age groups cannot be excluded. For instance, in countries like Belgium, Spiess and Schneider (2003) find an association between care-giving and reductions in work hours among women aged 45-59. Care-giving by grandparents could have an induced effect of the labor supply of their children (on this possibility see also Gielen 2009). All in all, the international evidence about the causal impact of subsidized part-time schemes on the employment rate of old workers remains mixed, with negative effects in Austria (Graf et al. 2011) and Portugal (Machado and Portela 2012) but positive ones in Germany (Huber et al. 2013).

At last, the ISP as a whole could have triggered a change in the perception of older workers on the labor market, which could potentially have a positive impact on both the demand and supply sides of the labor market. However, in view of the foregoing, the effect of the ISP on the employment rate of older workers are expected to be positive but small.

\section{Data and sample}

The outcome variable of our evaluation analysis is a national indicator of the quarterly salaried employment rate by gender and age group in the private sector. This indicator is built using administrative data on national salaried employment and on the population by gender and age group.

The quarterly number of private sector salaried employees by gender and age group is obtained from the National Social Security Office (ONSS) and is available since the first quarter of 1997 (1997q1). The analysis is restricted to the private sector for two reasons. First, the private employment is more reactive to fluctuations in the economic activity than the public employment. Second, the private sector, as opposed to the public sector, is targeted by all policies of the ISP. The salaried private employment is available in fourteen age groups. ${ }^{6}$ The data are adjusted for seasonality ${ }^{7}$ and corrected for a change in the classification that took place in 2003q1. ${ }^{8}$

The quarterly employment rate is obtained by dividing the quarterly salaried private employment of a particular gender and age group by the population of that same gender and age group of the corresponding year. ${ }^{9}$

The target of the ISP is the employment rate of older workers defined, in this paper, as people aged between 50 and 59 years old. Employed people aged 60 years old and over are not taken into account because the main hypothesis of the methodology used in this paper, responsiveness of the employment rate to fluctuation in economic activity, does not hold for them. People aged 45 to 49 years old are also left apart because they are not concerned by all policies of the ISP. A younger age group, formed by people aged 35-44 years old, is taken into account to investigate possible substitution or complementarity effects of the ISP. The private salaried employment rate by gender for the age group 


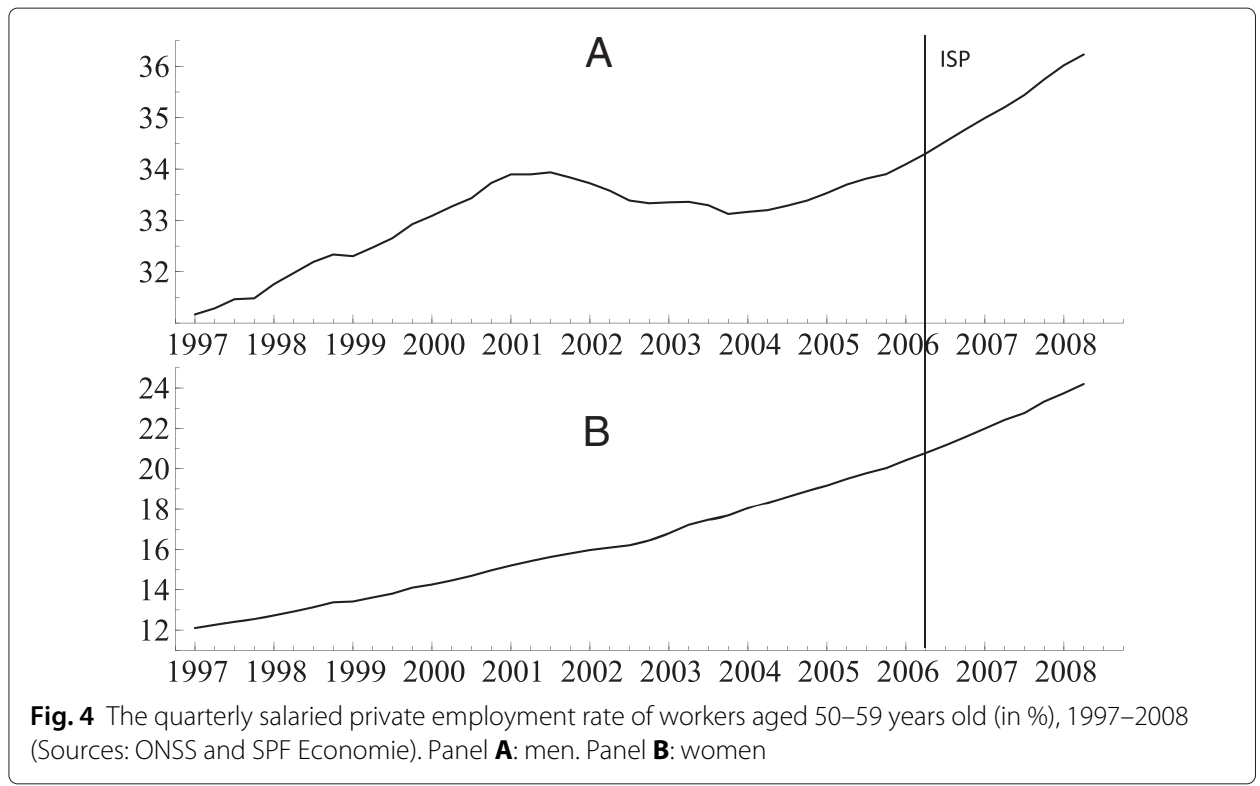

50-59 years old is depicted in Fig. 4. A slightly stronger rise in the employment rate of older workers appears in the years following the ISP for men. For older women, the overall evolution of the employment rate is dominated by an upward trend.

In this paper, the employment rate is explained by an indicator of the economic activity. The obvious candidate is the gross domestic product (GDP) measured by the seasonally adjusted Belgian quarterly real GDP from the National Bank of Belgium.

As already mentioned in the introduction, the sample is restricted to the period spanning from 1997q1 to 2008q2. The analysis stops at the beginning of the financial and economic crisis of 2008 because anti-crisis employment policies were taken by the government at that time. Thus after 2008q2, the effects of the policies of the ISP cannot be disentangled from those taken to counteract the effect of the crisis. Figure 5 shows the evolution of Belgian GDP for the period 1996q1-2008q2. Belgium underwent two

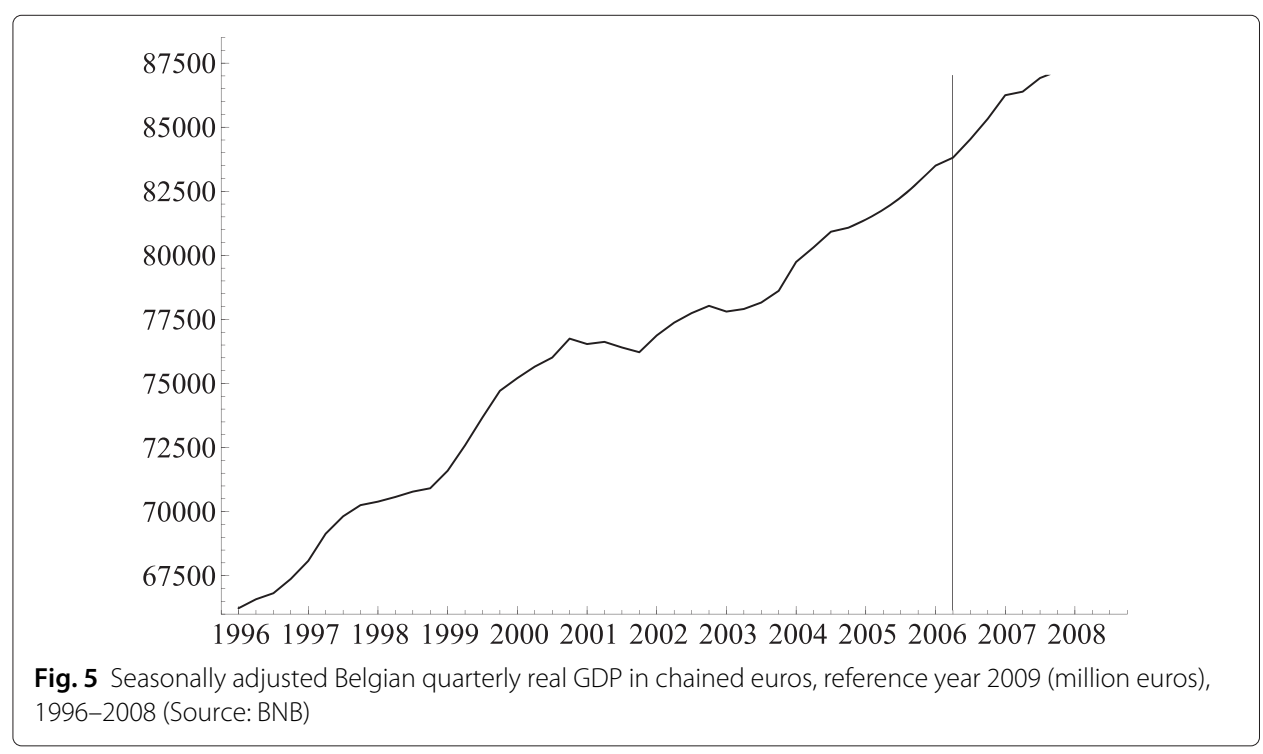


economic slowdowns, the first at the end of 2001 and the second at the end of 2002. Then, since 2003, the Belgian GDP grew steadily.

\section{The evaluation method}

This section is divided in two parts. The first describes the evaluation method, which is based on a counterfactual analysis. The second presents the macro-economeric regression model and discusses the potential simultaneity issue related to the model specification.

\subsection{The evaluation strategy in a nutshell}

The primary purpose of the paper is to measure the overall effectiveness of the ISP in raising the employment rate of workers aged 50-59 years old. To that purpose, we need to prove that without the ISP, i.e., in the counterfactual situation, the employment rate of these workers would have been smaller. In the present context, neither a control experiment nor a quasi-experimental design are available because the reforms apply to all workers aged 50 years or more. In the absence of control groups against which the impact of the ISP could be measured, we rely on an alternative strategy to recover the counterfactual scenario. Our method consists in comparing the actual evolution of the (gender and age specific) employment rate from the second quarter of 2007 to mid-2008 to a counterfactual evolution. The latter is the predicted evolution of the employment rate based on a macro-econometric model estimated over the period going from the first quarter of 1997 to the first quarter of 2007. The model explains quarterly variations in the employment rate by current and past levels of the real Belgian GDP, taking into account past dynamics of the dependent variable itself. As the forecast has to generate a convincing counterfactual, we cannot consider the cost of labor nor working hours of the older workers in the specification of the model simply because the ISP is affecting these variables (see the discussion of this point in the introduction).

The estimation period ends in 2007q1 from which the evaluation period takes over. As illustrated by Figs. 2 and 3, the strongest increase in the number of participants and expenditure is registered between 2006 and 2007, under the impulse of the RESSC for workers aged 50-56 years in April 2007. As a robustness check, we make the evaluation period start earlier in 2006q2 which corresponds to the introduction of the first policy of the ISP.

\subsection{The macro-econometric model}

As it is well known, most macro-economic variables are non-stationary series. According to the Augmented Dickey-Fuller (ADF) unit root tests, both the employment rate and GDP are integrated of order one in our data. ${ }^{10}$

Regressions based on variables integrated of order one are spurious unless they involve cointegrated variables. Could it be the case that there exists a long term equilibrium relationship between the employment rate and GDP? Due to the relative short time span of our data, a long term relationship between GDP and the employment rate in Belgium, if it exists, may be hard to identify. Being in the bivariate (two variables) case, the Engle and Granger (1987) test for cointegration is first used. Then as the Engle and Granger (1987) test has some important defects, ${ }^{11}$ the robustness of the results is checked using the Johansen (1988) cointegration test. The Engle and Granger (1987) and the Johansen 
(1988) tests differ concerning men aged 35-44 years old. The Engle and Granger (1987) test finds cointegration while the Johansen (1988) test does not. For all other age groups and gender, no cointegration is found between the employment rate and GDP. On the basis of those results, we make the assumption that there is no cointegration between the employment rate and GDP. ${ }^{12}$ These results confirm those of Bodart et al. (2009) who estimate an aggregate employment equation for Belgium for the period 1980-2002. They do not find a cointegration relationship between employment, GDP and the labor cost.

As no cointegration relationship was found between the employment rate and GDP, the model is estimated in first difference. The analysis is based on an autoregressive distributed lag model with the first difference of the employment rate as dependent variable and the growth rate of GDP as the explanatory variable. We allow past levels of GDP to influence current variations in the employment rate since the latter variable does not adjust immediately to changes in the economic activity. The model selection is automated using Autometrics ('Automatic general-to-specific selection', see Doornik 2009) on a general unrestricted model with four lags in the first difference of the employment rate and GDP growth rate:

$$
\Delta \mathrm{ER}_{g, a, t}=\alpha_{0}+\alpha_{1} t+\sum_{i=1}^{4} \phi_{i} \Delta \mathrm{ER}_{g, a, t-i}+\sum_{i=0}^{4} \gamma_{i} \Delta \log [\mathrm{GDP}]_{t-i}+\Delta \epsilon_{t}
$$

In equation $1, \Delta \mathrm{emp}_{g, a, t}$ stands for the first difference in the employment rate (ER) where the subscripts $g$ corresponds to gender, $a$ to age and $t$ to time. $\Delta \log [\mathrm{GDP}]_{t}$ is the growth rate of real GDP at time $t$. For women aged 50-59 and 35-44 years old, a linear trend is added to the regression as the first difference of the employment rate has a trend. We expect the coefficients of the growth rate of real GDP in equation 1 to be positive if the employment rate is to increase when GDP grows.

Given that we allow the employment rate at time $t$ to depend on the GDP growth rate at time $t$, it raises a potential simultaneity issue: GDP determines the employment rate, but the employment rate might also influence GDP. And this reverse causality may be induced by the ISP itself if it is effective in raising the employment rate of older workers. If there is no autocorrelation in the error terms of the models, a simultaneity bias may arise only when the best specification includes the contemporaneous value of GDP growth rate and not when it includes only lagged values. Even when the relationship is contemporaneous, the fact of working by age group and gender weakens the potential causality from the employment rate to GDP. This is particularly true for the main group of interest, the workers aged 50-59, as they constitute only $16 \%$ of total employment in Belgium (figures for 2007q1). As outlined in the next section, the contemporaneous value of GDP only appears in the regression models estimated for men. For those regressions, two robustness checks are implemented. The first one simply consists in removing the contemporaneous value of GDP. The second robustness analysis uses the mean real GDP of five neighboring countries (France, Luxembourg, Germany, the Netherlands and the U.K.) instead of the GDP of Belgium. As Belgium is a small open economy, the GDP of neighboring countries should have a great influence on the Belgian economic activity, and therefore on the employment rate. However, the real GDP of neighboring countries should not be affected (at least directly) by the gender and age specific employment rate in Belgium.

We estimate by OLS the model of equation 1 on the period 1997q1 to 2007q1 by agegroup and gender. Based on the estimated parameters, dynamic forecasts are generated 
over the period 2007q2 to 2008q2 (5 values are forecasted by age-group and gender). The model specifies the employment rate in first difference while the forecasted values of the employment rate should be in level. To retrieve these values, we rely on the identity equation defining the first difference of the employment rate. ${ }^{13}$ The forecasts are based on the estimated parameters but also on the lagged values of the employment rate and on the current and past values of GDP. For the lagged values of the employment rate, the actual values are used until 2007q1, after which the predicted values of the employment rate are exploited. For GDP, actual values are always used.

The evaluation strategy then consists in comparing, from 2007q2 onwards, the actual employment rate to the counterfactual (predicted) one. The difference between the actual and predicted employment rate represents the part of the employment rate that cannot be explained by its past dynamics and GDP. It is our estimator of the overall impact of the ISP. A $95 \%$ confidence interval around the predicted values is used to assess the significance of the estimated impact. If the actual employment rate is above (below) the upper (lower) bound of the confidence interval, there is a positive (negative) effect of the ISP on the employment rate.

\section{Results}

Table 1 shows the estimated parameters of the macro-econometric model specified in equation 1, by age-group (50-59 years old and 35-44 years old) and gender. The coefficients of the growth rate of GDP are significant at the $1 \%$ or $5 \%$ level for each gender and age group. As expected, an increase in (current or past) GDP has a positive impact on the employment rate. It is worth noting that the estimated effects of GDP are larger for men than for women, irrespective of the age group, and decrease with age.

The results of three hypothesis tests (absence of autocorrelation, normality and homoscedasticity of the error terms) are reported at the bottom of Table 1 . The null

Table 1 The quarterly variation of the salaried private employment rate by age group and gender OLS estimates

\begin{tabular}{|c|c|c|c|c|}
\hline \multirow[t]{3}{*}{ Dep. var. } & \multicolumn{4}{|c|}{$\Delta$ Employment rate } \\
\hline & \multicolumn{2}{|c|}{ 50-59 years old } & \multicolumn{2}{|c|}{$35-44$ years old } \\
\hline & Men & Women & Men & Women \\
\hline \multirow[t]{2}{*}{$\Delta$ Employment rate $_{t-1}$} & $0.533^{* * *}$ & & $0.418^{* * *}$ & \\
\hline & $(0.103)$ & & $(0.117)$ & \\
\hline \multirow[t]{2}{*}{$\Delta \log [\mathrm{GDP}]_{t}$} & $0.087^{* * *}$ & & $0.127^{* * *}$ & \\
\hline & $(0.027)$ & & $(0.036)$ & \\
\hline \multirow[t]{2}{*}{$\Delta \log [G D P]_{t-3}$} & $0.115^{* * *}$ & $0.048^{* *}$ & $0.153^{* * *}$ & $0.127^{* * *}$ \\
\hline & $(0.028)$ & $(0.021)$ & $(0.039)$ & $(0.041)$ \\
\hline \multirow[t]{2}{*}{ Constant } & $-0.071^{* * *}$ & $0.066^{* *}$ & -0.054 & $0.134^{* *}$ \\
\hline & $(0.026)$ & $(0.029)$ & $(0.036)$ & $(0.056)$ \\
\hline \multirow[t]{2}{*}{ Trend } & & $0.006^{* * *}$ & & $0.003^{*}$ \\
\hline & & $(0.001)$ & & $(0.002)$ \\
\hline Nbr obs. & 39 & 40 & 39 & 40 \\
\hline$R^{2}$ & 0.697 & 0.574 & 0.633 & 0.228 \\
\hline $\operatorname{Adj} . R^{2}$ & 0.671 & 0.551 & 0.601 & 0.187 \\
\hline Serial correlation (AR 1-3) ${ }^{a}$ & $F(3,32)=1.112$ & $F(3,34)=0.559$ & $F(3,32)=0.998$ & $F(3,34)=1.566$ \\
\hline Normality test & $\operatorname{Chi}^{2}(2)=1.3$ & $\mathrm{Chi}^{2}(2)=0.725$ & $\mathrm{Chi}^{2}(2)=1.286$ & $\mathrm{Chi}^{2}(2)=0.468$ \\
\hline Heteroscedasticity test ${ }^{b}$ & $F(6,32)=0.686$ & $F(4,35)=0.849$ & $F(6,32)=0.284$ & $F(4,35)=2.155$ \\
\hline
\end{tabular}

${ }^{a}$ Durbin's alternative test for serial correlation without strictly exogenous regressors. ${ }^{b}$ White test for heteroscedasticity.

***significant at $1 \%$ level, ${ }^{* *} 5 \%$ level, ${ }^{*} 10 \%$ level. The model selection is automated using Autometrics 
hypothesis of no serial correlation, normality and homoscedasticity cannot be rejected at conventional significance levels. Since there is no evidence of autocorrelation of the error terms, simultaneity is likely to be an issue only if the best specification includes the contemporaneous value of GDP growth rate (i.e., for men).

This section proceeds by presenting the estimated effect of the ISP on the quarterly age and gender-specific employment rates. We then investigate the sensitivity of the results to alternative specifications and indicators of the economic activity.

\subsection{The effect of the ISP}

The estimated effect of the ISP on the employment rate can be depicted graphically. In Fig. 6, the solid line corresponds to the observed employment rate. The dashed line corresponds to its fitted values up to 2007q1 and to its predicted values from 2007q2 onwards. The vertical bars represent the $95 \%$ confidence interval around the forecasts.

For workers aged between 50 and 59 years old, both the observed and predicted values of the employment rate have been increasing since 2007q2 for both genders. So, even in the absence of the ISP, the employment rate of older workers would have increased as the result of the good economic conditions at that time. Still, Fig. 6 indicates that this rise would have been lower in the absence of the ISP, the actual level of the employment rate being above the predicted one for both genders, although less obviously for women. From this figure, we can therefore confirm a positive impact of the ISP on the employment rate of older workers, which seems to have risen steadily since its implementation. Given that the confidence interval of the forecasts includes the observed value of the employment rate for both genders, we can however not conclude that there is a statistically significant impact at a level of $5 \%$.

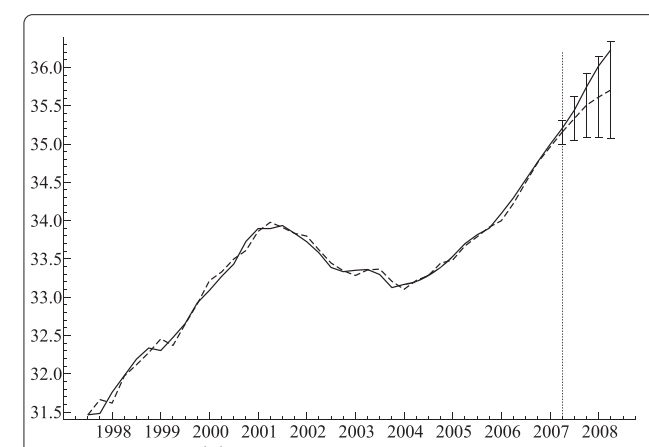

(a) Men aged 50-59 years old

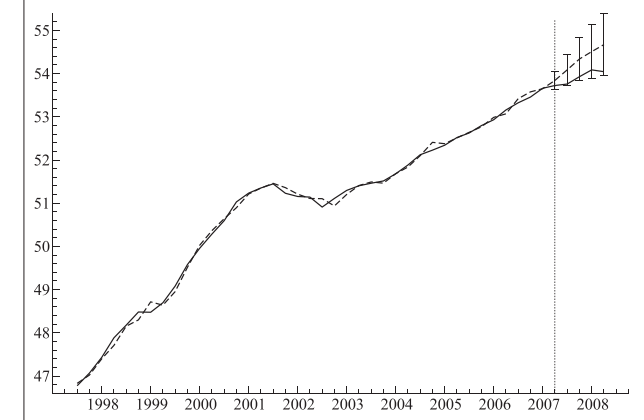

(c) Men aged 35-44 years old

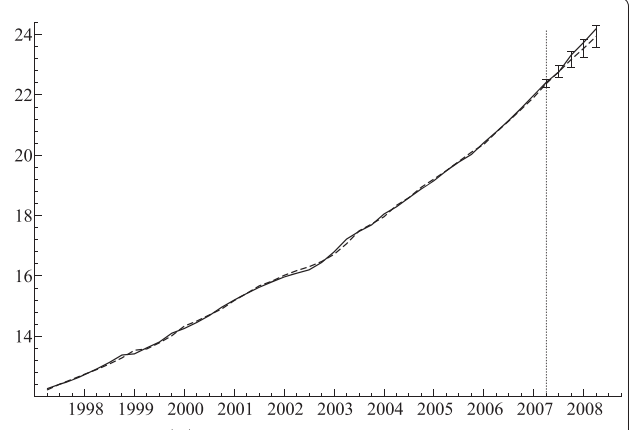

(b) Women aged 50-59 years old

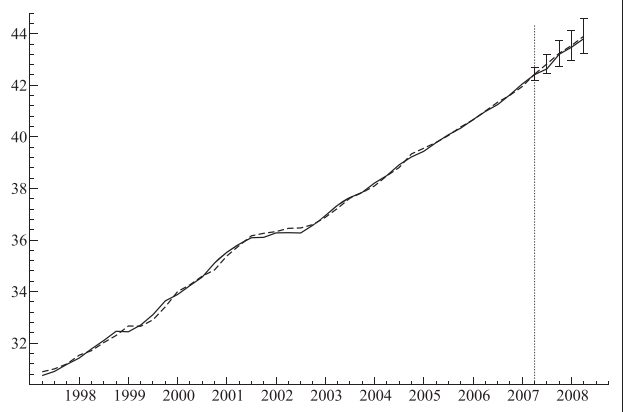

(d) Women aged 35-44 years old

Fig. 6 The quarterly salaried private employment rate (in \%), 1997q2-2008q2, — observed series, - - - fitted values and forecasts from $2007 q 2, \vdash \dashv 95 \% \mathrm{Cl}$ of the forecasts 
Table 2 The impact of the ISP on the quarterly salaried private employment (rate) of workers aged 50-59 in 2008q2, by gender

\begin{tabular}{|c|c|c|c|}
\hline & $\begin{array}{l}\text { Observed } \\
\text { value }\end{array}$ & $\begin{array}{l}\text { Predicted } \\
\text { value (s.e.) }\end{array}$ & $\begin{array}{l}\text { Impact in \% } \\
\text { points }^{a} \text { (s.e.) }\end{array}$ \\
\hline \multicolumn{4}{|l|}{ Employment rate } \\
\hline Men aged 50-59 & $36.23 \%$ & $35.71 \%(0.31)$ & $0.52(0.31)$ \\
\hline $95 \% \mathrm{Cl}$ & & {$[35.07 ; 36.34]$} & \\
\hline $90 \% \mathrm{Cl}$ & & {$[35.18 ; 36.24]$} & \\
\hline Women aged 50-59 & $24.20 \%$ & $23.94 \%(0.18)$ & $0.26(0.18)$ \\
\hline $95 \% \mathrm{Cl}$ & & {$[23.58 ; 24.30]$} & \\
\hline $90 \% \mathrm{Cl}$ & & {$[23.64 ; 24.24]$} & \\
\hline \multicolumn{4}{|l|}{ Employment } \\
\hline Men aged 50-59 & 258,178 & 254,439 & 3,739 \\
\hline Women aged 50-59 & 172,366 & 170,553 & 1,813 \\
\hline
\end{tabular}

${ }^{a}$ The impact is measured as the difference between the observed and the predicted value

In Table 2, we report the estimated impact of the ISP in 2008q2 (i.e., the estimated difference between the observed and predicted value of the employment rate at that da) together with its standard deviation. The impact, although positive, is not significant at conventional levels. In 2008q2, the observed employment rate of men aged 50-59 is $36.23 \%$, while the predicted one is $35.71 \%$. The gap, which is our measure of impact, is only 0.52 of a percentage point, which represents only $1.46 \%$ of the predicted value. This corresponds to approximately 3,700 additional jobs due to the ISP. For women aged 5059 , the observed and predicted employment rates are, respectively, $24.20 \%$ and $23.94 \%$. So the impact is smaller, 0.26 of a percentage point, which corresponds to $1.09 \%$ of the predicted employment rate for older women and an additional job creation of about 1,800 units. There is an overlap in the $95 \%$ confidence intervals of the estimated effect for men and women. So even if the effect is larger for men than for women, we can not reject that both effects are the same, and equal to zero.

For younger men aged 35-44 (see panel (c) in Fig. 6, as well as Table 3), both the observed and predicted values of the employment rate have also been increasing since 2007q2. However, since the actual level of the employment rate is below the predicted one, the employment rate of men aged 35-44 would have been higher in the absence of the ISP. This result therefore points to a negative impact of the ISP on the younger age group,

Table 3 The impact of the ISP on the quarterly salaried private employment (rate) of workers aged $35-44$ in 2008q2, by gender

\begin{tabular}{rlll}
\hline & $\begin{array}{l}\text { Observed } \\
\text { value }\end{array}$ & $\begin{array}{l}\text { Predicted } \\
\text { value (s.e.) }\end{array}$ & $\begin{array}{l}\text { Impact in \% } \\
\text { points }{ }^{a} \text { (s.e.) }\end{array}$ \\
\hline Employment rate & & & $-0.63(0.36)$ \\
\hline Men aged 35-44 & $54.04 \%$ & $54.67 \%(0.36)$ & \\
$90 \% \mathrm{Cl}$ & & {$[53.93 ; 55.41]$} & $-0.1(0.34)$ \\
Women aged 35-44 & & $454.06 ; 55.28]$ & \\
$95 \% \mathrm{Cl}$ & $43.81 \%$ & {$[43.91 \%(0.34)$} & \\
\hline Employment & & {$[43.32 ; 44.49]$} & \\
\hline Men aged 35-44 & & & $-4,976$ \\
Women aged 35-44 & & 433,711 & -759 \\
\hline
\end{tabular}

${ }^{a}$ The impact is measured as the difference between the observed and the predicted value 
suggesting a potential substitution effect. Based on Table 3, this negative effect is however not statistically significant at even $10 \%$. For men aged $35-44$ years old, the observed value of the employment rate in $2008 \mathrm{q} 2$ is $54.04 \%$, while the predicted, counterfactual value is $54.67 \%$. The gap, which is our measure of impact, is -0.63 of a percentage point, which amounts to about 4,976 jobs lost. For younger women aged 35-44 (see panel (d) in Fig. 6, as well as Table 3), there is nearly no difference between the observed values and the forecasts from $2007 \mathrm{q} 2$ onwards. The estimated impact is still negative, -0.10 (759 jobs lost), but not at all significant.

In sum, the point estimates suggest that there could be a small positive impact of the ISP on the employment rate of older workers. Consistent with this finding, the results suggest a small negative impact for younger workers, which could be interpreted as a substitution effect. However, since the standard deviation of the estimated effects is quite large in relation to their magnitude, we cannot confirm to a significant impact of the ISP.

As explained in sub-section 2.2.3, we expect a positive but small overall impact of the ISP on the employment rate of older workers. In that context, the probability of detecting a statistically significant impact depends crucially on the standard deviations of the forecasts. These in turn depend on the goodness of fit of the macro-econometric model $\left(R^{2}\right)$ and the standard errors of the estimated parameters reported in Table 1. For identification purposes, we had to rely on a relatively simple model of the employment rate as reflected in the relatively low $R^{2}$, especially for women. This is therefore the price we pay for trying to identify a causal effect of the ISP. Although nothing can be done about it, the small size of our sample also induces less precision in the estimated parameters and so widens the confidence intervals around the forecasts.

\subsection{Robustness checks}

As a first robustness check, we make the evaluation period start one year earlier, in 2006q2, which corresponds to the introduction of the first policy of the ISP. The results of this robustness analysis are depicted in Fig. 7. For workers aged 50-59, a positive impact of the ISP is still visible in the graphs, more markedly for men. For workers aged 35-44, the conclusion of a negative impact of the ISP is maintained, although this is only visible for men. For both age groups, the divergence between the predicted and observed values of the employment rate appears earlier, at the beginning of 2006 for the older age group, between the second and third quarter of 2006 for the youngest one. These results suggest that the ISP could have had an impact from the beginning of its implementation. Still, the estimated effects are not statistically significant at conventional levels.

The second robustness check investigates whether the results are sensitive to a potential simultaneity bias. Such a bias arises only when the contemporaneous GDP growth rate appears in the regressors. This is the case for men of both age groups. Two sensitivity analyses are therefore made for this specific gender. The first one consists in removing the contemporaneous value of GDP of the regression model and the second takes the mean real GDP of France, Luxembourg, Germany, the Netherlands and the U.K. as a regressor instead of Belgian GDP.

Table 4 gives the OLS estimates of the two sensitivity analyses. The null hypothesis of no serial correlation, normality and homoscedasticity cannot be rejected at conventional significance levels for both analysis and age groups. The estimated parameters of the model without the contemporaneous value of GDP growth rate are very close to those 


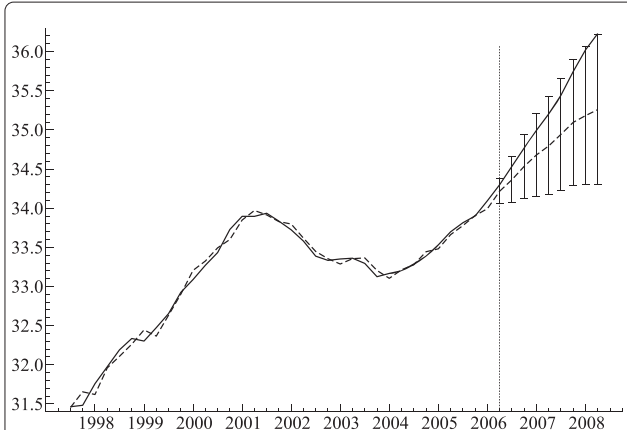

(a) Men aged 50-59 years old

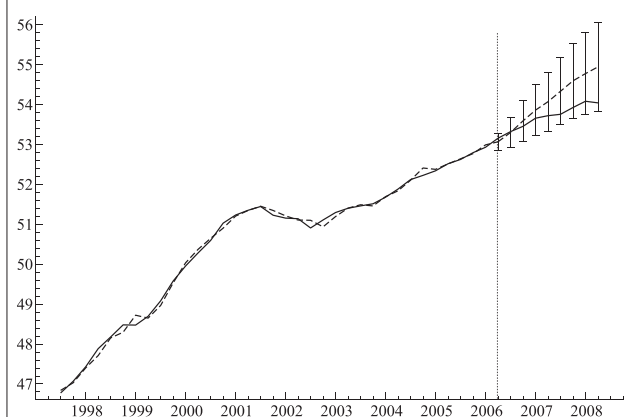

(c) Men aged 35-44 years old

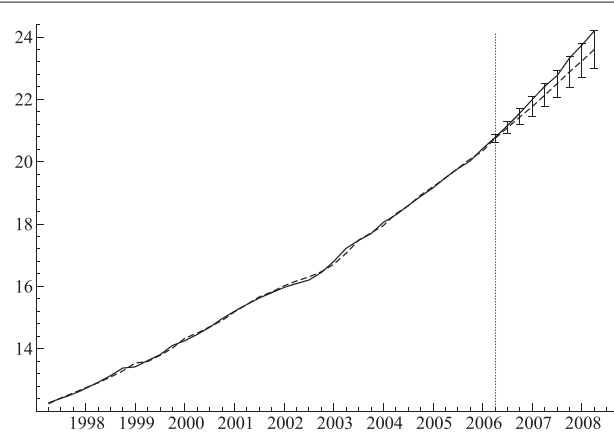

(b) Women aged 50-59 years old

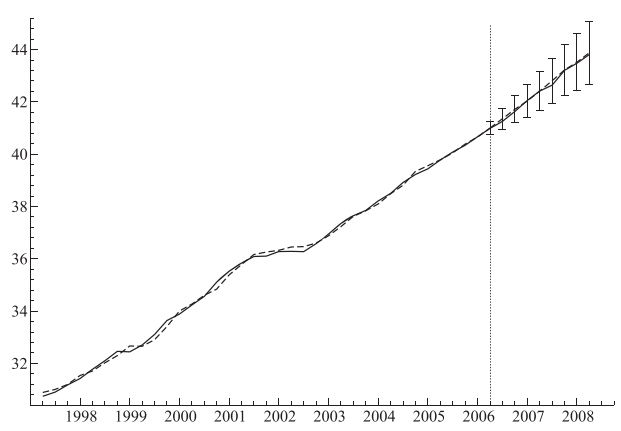

(d) Women aged 35-44 years old

Fig. 7 The quarterly salaried private employment rate (in \%), 1997q2-2008q2, — observed series, - - - fitted values and forecasts from $2006 q 2, \vdash \dashv 95 \% \mathrm{Cl}$ of the forecasts

Table 4 The quarterly variation of the male salaried private employment rate by age group, with alternative specifications of GDP - OLS estimates

\begin{tabular}{|c|c|c|c|c|}
\hline \multirow{3}{*}{$\begin{array}{l}\text { Dep. var. } \\
\Delta \text { Employment rate }_{t-1}\end{array}$} & \multicolumn{4}{|c|}{$\Delta$ Employment rate Men } \\
\hline & \multicolumn{2}{|c|}{ 50-59 years old } & \multicolumn{2}{|c|}{$35-44$ years old } \\
\hline & $0.553^{* * *}$ & $0.461^{* * *}$ & $0.387^{* * *}$ & $0.360^{* *}$ \\
\hline & $(0.116)$ & $(0.128)$ & $(0.134)$ & $(0.154)$ \\
\hline \multirow[t]{2}{*}{$\Delta \log [G D P]_{t-3}$} & $0.102^{* * *}$ & & $0.142^{* * *}$ & \\
\hline & $(0.031)$ & & $(0.045)$ & \\
\hline \multirow[t]{2}{*}{$\Delta \log [G D P \text { neighbors }]_{t}$} & & 0.031 & & 0.053 \\
\hline & & $(0.033)$ & & $(0.046)$ \\
\hline \multirow[t]{2}{*}{$\Delta \log [G D P \text { neighbors }]_{t-3}$} & & $0.132^{* * *}$ & & $0.125^{* *}$ \\
\hline & & $(0.032)$ & & $(0.052)$ \\
\hline \multirow[t]{2}{*}{ Constant } & -0.015 & $-0.064^{*}$ & 0.03 & -0.010 \\
\hline & $(0.022)$ & $(0.032)$ & $(0.03)$ & $(0.047)$ \\
\hline Nbr obs. & 39 & 39 & 39 & 39 \\
\hline$R^{2}$ & 0.605 & 0.657 & 0.502 & 0.464 \\
\hline Adj. $R^{2}$ & 0.583 & 0.627 & 0.474 & 0.418 \\
\hline Serial correlation (AR 1-3) ${ }^{a}$ & $F(3,33)=0.317$ & $F(3,32)=0.468$ & $F(3,33)=0.115$ & $F(3,32)=0.148$ \\
\hline Normality test & $\mathrm{Chi}^{2}(2)=0.376$ & $\mathrm{Chi}^{2}(2)=2.867$ & $\mathrm{Chi}^{2}(2)=0.516$ & $\mathrm{Chi}^{2}(2)=8.094$ \\
\hline Heteroscedasticity test ${ }^{b}$ & $F(4,34)=0.125$ & $F(6,32)=0.816$ & $F(4,34)=1.159$ & $F(6,32)=0.448$ \\
\hline
\end{tabular}

${ }^{a}$ Durbin's alternative test for serial correlation without strictly exogenous regressors. ${ }^{b}$ White test for heteroscedasticity.

***significant at $1 \%$ level, ${ }^{* *} 5 \%$ level, ${ }^{*} 10 \%$ level. The model selection is automated using Autometrics 


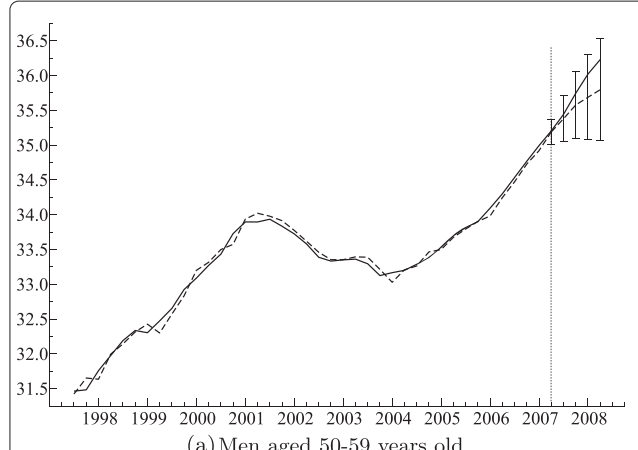

(a) Men aged 50-59 years old

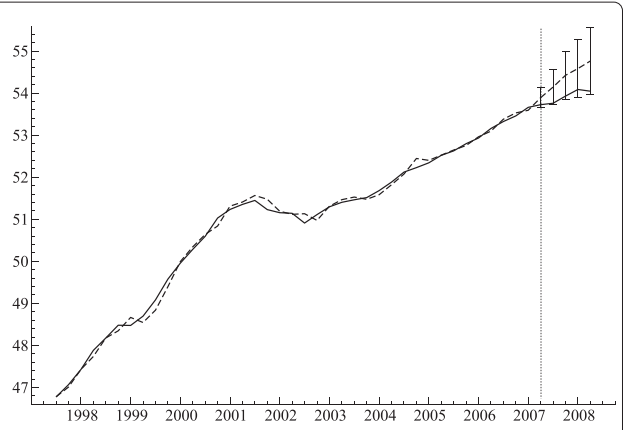

(b) Men aged 35-44 years old

Fig. 8 The quarterly salaried private employment rate (in \%), 1997q2-2008q2, — observed series, - - - fitted values and forecasts from 2007q2 based on lagged values of GDP only, $\vdash \dashv 95 \% \mathrm{Cl}$ of the forecasts

including it. Using the GDP of neighboring countries, only the third lag is statistically significant for both age groups, and the point estimates are again not too far from those estimated in the baseline model. However, the $R^{2}$ decreases for both age groups as compared to the baseline model of Table 1, above all for men aged 35-44 years old.

The estimated impact of the ISP under these two alternative specifications are given in Figs. 8 and 9. As the $R^{2}$ are smaller, the confidence intervals are wider compared to the baseline analysis, but the results are maintained. The point estimates indicate a possible small positive impact of the ISP for men aged 50-59 and a small negative impact for younger men. Though, the results are not statistically significant at even $10 \%$. Table 5 reports the estimated impacts of the ISP in 2008q2 for men aged 50-59 under both specifications. Their $95 \%$ confidence interval overlaps the ones of the baseline estimated impacts.

\section{Conclusion}

The primary aim of this paper is to evaluate the overall impact of the active aging policies introduced by the Intergenerational Solidarity Pact (ISP) in December 2005 on the employment rate of workers aged 50-59 in Belgium. The possible substitution or complementarity effects of the ISP on the employment rate of a younger age group (those aged 35-44) are also investigated. The impacts of the reforms introduced by the ISP are measured over the period 2007q2-2008q2 and assessed through a counterfactual analysis.

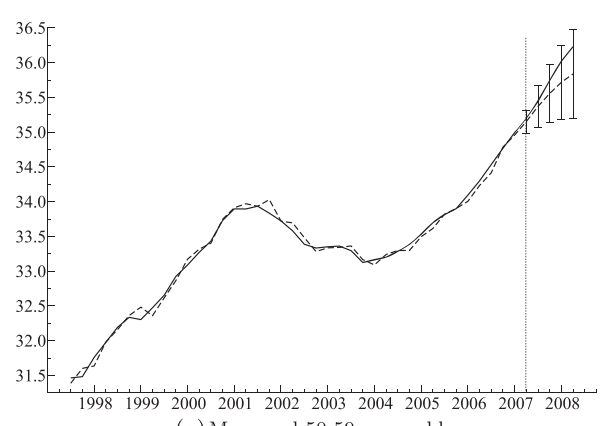

(a) Men aged 50-59 years old

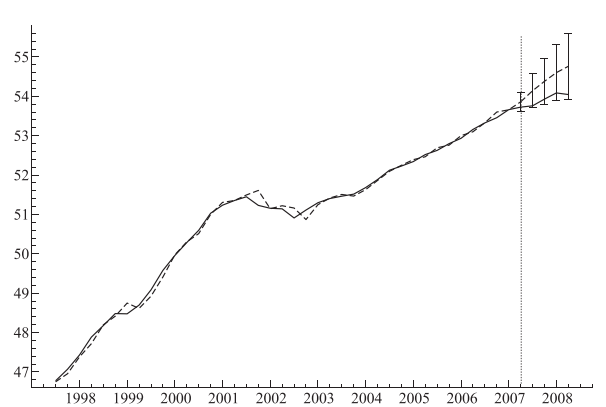

(b) Men aged 35-44 years old

Fig. 9 The quarterly salaried private employment rate (in \%), 1997q2-2008q2, — observed series, - - - fitted values and forecasts from 2007q2 based on GDP of neighbors, $\vdash-195 \% \mathrm{Cl}$ of the forecasts 
Table 5 The impact of the ISP on the quarterly salaried private employment (rate) of male workers aged 50-59 in 2008q2 with alternative specifications of GDP

\begin{tabular}{|c|c|c|c|}
\hline & $\begin{array}{l}\text { Observed } \\
\text { value }\end{array}$ & $\begin{array}{l}\text { Predicted } \\
\text { value (s.e.) }\end{array}$ & $\begin{array}{l}\text { Impact in \% } \\
\text { points }^{a}\end{array}$ \\
\hline \multicolumn{4}{|c|}{ Regressions without the contemporaneous value of GDP } \\
\hline Employment rate & $36.23 \%$ & $35.80 \%$ & 0.43 \\
\hline $95 \% \mathrm{Cl}$ & & {$[35.06 ; 36.53]$} & \\
\hline $90 \% \mathrm{Cl}$ & & {$[35.18 ; 36.41]$} & \\
\hline Employment & 258,178 & 255,087 & 3,091 \\
\hline \multicolumn{4}{|c|}{ Regressions using GDP of neighbors } \\
\hline Employment rate & $36.23 \%$ & $35.84 \%$ & 0.39 \\
\hline $95 \% \mathrm{Cl}$ & & {$[35.19 ; 36.49]$} & \\
\hline $90 \% \mathrm{Cl}$ & & {$[35.30 ; 36.38]$} & \\
\hline Employment & 258,178 & 255,379 & 2,799 \\
\hline
\end{tabular}

${ }^{a}$ The impact is measured by the difference between the observed and the predicted value

The observed values of the employment rate are compared to their predicted (counterfactual) values based on a macro-econometric model estimated over a period of time preceding the implementation of the ISP. The motivation of this paper is the scarcity of empirical research about the overall impact of labor market reforms, especially in Belgium, despite their importance for policy making.

The main identification hypothesis of our evaluation method is that, in the absence of the ISP, changes in the employment rate would have been closely linked to the GDP growth rate. As the predicted values have to generate a convincing counterfactual, we cannot consider the cost of labor nor working hours of the older workers in the model specification simply because the ISP is affecting these variables mainly through two policies, i.e., the reduction in employers' social security contributions and the working time reduction with (partial) wage compensation. The size of this influence can hardly be predicted without a structural model of wages and hours worked. Developing such a model is beyond the scope of this paper. Besides, we did not find any major shock other than the ISP that could have had a substantial influence on the employment rate of the older workers at that time. Now, if the ISP itself is effective in raising the employment rate of older workers, this can induce reverse causality between the employment rate and the GDP growth rate. This is the reason why we use the mean real GDP of five neighboring countries (France, Luxembourg, Germany, the Netherlands and the U.K.) instead of the GDP of Belgium in a sensitivity analysis.

The results show that if there is a positive impact of the ISP, it is too small to be statistically significant. For men aged $50-59$, the impact is only 0.52 (s.e. 0.31 ) of a percentage point, rising the employment rate from $35.7 \%$ to $36.2 \%$, while for women aged 50-59, the impact is 0.26 (s.e. 0.18 ) of a percentage point, increasing the employment rate from $23.9 \%$ to $24.2 \%$. Moreover, the results suggest a small negative effect on the employment rate of younger workers. For men aged 35-44 years old, the impact is -0.63 (s.e. 0.36) of a percentage point, decreasing the employment rate from $54.7 \%$ to $54.0 \%$. For younger women, the impact is -0.10 (s.e. 0.34 ) percentage point. Even if the effects are larger in absolute value for men than for women, we cannot reject that both effects are the same and not significantly different from zero. In sum, the results suggest a slight positive impact of the ISP on the employment rate of older workers at the expense of younger workers. However, there seems to be a lack of statistical power to draw firm conclusions 
on the overall effect of the ISP. A low sample size is certainly part of the explanation, as well as a relatively low goodness of fit of the macro-econometric model. For identification purposes, we had indeed to rely on a somewhat simple model of the employment rate. This is the price we pay for trying to identify a causal effect of the ISP.

\section{Endnotes}

${ }^{1}$ For the period from January 2003 to December 2005, the legal retirement age was 63 for women. It reached 64 in January 2006 and 65 in January 2009.

${ }^{2}$ Some policies have already been taken before: the above-mentioned increase in the legal retirement age of women; the introduction of RESSC at the age of 58 (respectively, 57) in 2002 (respectively, 2004); the part-time time-credit for people aged at least 50 introduced in 2002; an in-work benefit (Complément reprise du travail) paid when an unemployed aged 50 years old and over finds a job after a sufficiently long career (introduced in 2002 as well); beyond a given unemployment duration, a temporary hiring subsidy for people aged at least 50 (the Plan Avantage à l'embauche) since 1995. The latter policy has been replaced in 2002 by a similar scheme for those at least 45 years old (the Plan Activa).

${ }^{3}$ The allowance is then not subject to social security contributions as it is the case when the allowance is paid to an unemployed worker.

${ }^{4} \mathrm{~A}$ presumably minor part of this increase is driven by the extension of the RESSC to workers aged 57 or more in 2004 (instead of 58 before).

${ }^{5} \mathrm{~A}$ reputation effect could also play a role. When wages increase with seniority, the deferred payment acts as an incentive device provided that the firm is not publicly known to renege on the promise of higher future wages. Finally, firing an old worker (instead of a younger one) could in some cases lead to an appeal against this decision on the basis of a discriminatory argument.

${ }^{6}<18$; 18-19; 20-21; 22-24; 25-29; 30-34; 35-39; 40-44; 45-49; 50-54; 55-59; 60-64; $\geq 65$; missing.

${ }^{7}$ For seasonal adjustment, we use the software developed by Eurostat, Demetra+, with the specification X12ARIMA RSA5C.

${ }^{8}$ During the first semester of 2003, the composition of employment measured by the ONSS changed due to harmonization between the different Belgian social security bodies. The dataset used in this paper is concerned with the introduction of two new categories of workers: disabled workers with more than 12 months of incapacity and people working in childcare. As a consequence, a level shift shows up in the employment data in 2003q1. To prevent those changes from having an impact on this analysis, the data are corrected before the statistical analysis. Because data on disabled workers and people working in childcare are not available by gender and age group for the period 1997-2002, the adjustment is made by replacing the permanent blip in the first difference of the employment by a linear interpolation and then rebuilding the level of employment before 2003 using this new first difference for 2003q1. This approach follows the method proposed by Nielsen (2004) for additive outliers.

${ }^{9}$ The data on the population by gender and age group are annual and measured as the resident population on the $1^{\text {st }}$ of January of each year (National Register of Population, SPF Economie). The population is available in 12 age groups (15-19; 20-24; 25-29; 30-34; $35-39 ; 40-44 ; 45-49 ; 50-54 ; 55-59 ; 60-64 ; \geq 65)$. As the employment data in the numerator of the employment rate are quarterly data, the annual population data are transformed in quarterly data. The data of January for a given year are assigned to the fourth quarter of the previous year.

${ }^{10}$ The results of ADF tests are available from the authors upon request.

${ }^{11}$ The Engle-Granger methodology is limited to a single-equation test, which is problematic as the equilibrium relationship could be expressed in two ways (the employment rate as a function of GDP or GDP as a function of the employment rate). 
Two Engle-Granger tests could therefore be performed (one using the employment rate as a function of GDP and the other GDP as a function of the employment rate). As the sample size grows infinitely large, the two tests become equivalent, but in a small sample, the results might differ, which is a very undesirable feature (Enders 1995). Moreover, the Engle-Granger test relies on a two-step estimator. Hence, errors introduced in the first step are carried into the second one (Enders 1995).

${ }^{12}$ The results of the Engle and Granger (1987) and the Johansen (1988) tests are available from the authors upon request.

$$
{ }^{13} \Delta \mathrm{ER}_{g, a, t}=\mathrm{ER}_{g, a, t}-\mathrm{ER}_{g, a, t-1} \text {. }
$$

\title{
Competing interests
}

The IZA Journal of Labor Policy is committed to the IZA Guiding Principles of Research Integrity. The authors declare that they observed these principles.

\section{Authors' information}

Catherine Smith contributed to this paper when she was affiliated to IRES, Université Catholique de Louvain.

\author{
Acknowledgements \\ We are grateful to the referees, the editor, Sophie Béreau, Vincent Bodart, Bart Cockx, Arnaud Dufays and William Pariente \\ for their very useful comments. We thank in particular Fatemeh Shadman. We also thank participants to various seminars \\ in Louvain-la-Neuve and to the Belgian Day of labor Economists in Leuven (December 2012) for their comments and \\ suggestions. The usual caveat applies. We finally thank the Belgian Federal Administration Science Policy for its financial \\ support on the project "Age, women and employment: An evaluation" within the program Society and Future \\ (CONTRACT NRTA/00/044).
}

Responsible editor: Juan F Jimeno

\section{Author details}

${ }^{1}$ IRES - Université catholique de Louvain, Louvain-la-Neuve, Belgium. ${ }^{2}$ Fonds de la Recherche Scientifique-FNRS, Brussels, Belgium. ${ }^{3}$ IZA.

Received: 12 June 2014 Accepted: 2 June 2015

Published online: 10 September 2015

\section{References}

Albanese A, Cockx B (2015) Permanent wage cost subsidies for older workers: An effective tool for increasing working time and postponing early retirement? Mimeo, SHERPPA, Ghent University

Bassilière D, Bossier F, Lebrun I, Stockman P (2007) Le programme national de réforme de la belgique. effets macroéconomiques de réductions de charges sur le travail. WORKING PAPER 11-07, Bureau fédéral du Plan

Bodart V, Ledent P, Shadman-Metha F (2009) An employment equation for belgium. Discussion Papers (IRES - Institut de Recherches Economiques et Sociales) 2009016, Université catholique de Louvain, Institut de Recherches Economiques et Sociales (IRES). http://ideas.repec.org/p/ctl/louvir/2009016.html

Bryan ML (2007) Free to choose? Differences in the hours determination of constrained and unconstrained workers. Oxf Econ Pap 59(2):226-252

Calmfors L, Skedinger P (1995) Does active labour-market policy increase employment? Theoretical considerations and some empirical evidence from Sweden. Oxf Rev Econ Policy 11(1):91-109

Cataldi A, Kampelmann S, Rycx F (2012) Does it pay to be productive? the case of age groups. Int J Manpow 33:264-283

de Koning J (1993) Measuring the placement effects of two wage-subsidy schemes for the long-term unemployed. Empirical Econ 18(3):447-468

Decicca C (2007) Hours flexibility and retirement. Econ Inq 45(2):251-267

Devisscher S, Sanders D (2007) Ageing and life-course issues: The case of the career break scheme (belgium) and the life-course regulation (netherlands). Modernising Social Policy for the New Life Course. OECD 2007. pp 117-132

Dmitrijeva J, Hazans M (2007) A stock-flow matching approach to evaluation of public training programme in a high unemployment environment. Labour 21(3):503-540

Doornik JA (2009) Autometrics. In: Castle JL, Shephard N (eds). The Methodology and Practice of Econometrics, Chapter 4. Oxford University Press. pp 88-121

Enders W (1995) Applied Econometric Times Series. Wiley Series in Probability and Mathematical Statistics. John Wiley and Sons Inc., New York

Engle RF, Granger CWJ (1987) Cointegration and error-correction: Representation, estimation, and testing. Econometrica 55(2):251-276

Euwals R (2001) Female labour supply, flexibility of working hours, and job mobility. Econ J 111(471):120-34

Fahr R, Sunde U (2009) Did the Hartz reform speed-up the matching process? a macro- evaluation using empirical matching functions. German Econ Rev 10(3):284-316

Gielen A (2009) Working hours flexibility and older workers' labor supply. Oxf Econ Pap 61:240-274

Graf N, Hofer H, Winter-Ebmer R (2011) Labor supply effects of a subsidized old-age part-time scheme in austria. Zeitschrift für ArbeitsmarktForschung - J Labour Mark Res 44:217-229

Gustman AL, Steinmeier TL (1983) Minimum hours constraints and retirement behavior. NBER Working Papers 0940, Nat Bur Econ Res Inc. http://ideas.repec.org/p/nbr/nberwo/0940.html 
Hertweck MS, Sigrist O (2013) The aggregate effects of the hartz reforms in germany. Working papers 2013/01, Faculty of Business and Economics - University of Basel. http://ideas.repec.org/p/bsl/wpaper/2013-01.html

Huber M, Lechner M, Wunsch C (2013) The effect of firms' partial retirement policies on the labour market outcomes of their employees. Technical Report 7513, IZA, Institute for the Study of Labor

Hujer R, Blien U, Caliendo M, Zeiss C (2002) Macroeconometric evaluation of active labour market policies in germany - a dynamic panel approach using regional data. IZA Discussion Papers 616, Institute for the Study of Labor (IZA). http:// ideas.repec.org/p/iza/izadps/dp616.html

Jackman R, Pissarides CA, Savouri S (1990) Labour market policies and unemployment in the OECD. Econ Policy 5:450-490

Johansen S (1988) Statistical analysis of cointegration vectors. J Econ Dynamics Control 12:231-254

Jousten A, Lefebvre M, Perelman S (2013) Health status, disability and retirement incentives in belgium. Working Paper 7783, IZA, Institute for Labor Economics

Kahn SB, Lang K (1995) The causes of hours constraints: Evidence from Canada. Can J Econ 28(4a):914-28

Klinger S, Rothe T (2012) The impact of labour market reforms and economic performance on the matching of short-term and long-term unemployed. Scott J Pol Econ 59(1):90-114

Kopits GF (1978) Wage subsidies and employment: An analysis of the French experience. Staff Pap Int Monetary Fund 25(3):494-527

Layard R, Nickell S, Jackman R (1991) Unemployment: Macroeconomic Performance and the Labour Market. OUP Catalogue, Vol. 9780198284345 . Oxford University Press. http://ideas.repec.org/b/oxp/obooks/9780198284345.html

Lefevre M, Orsini K (2011) A structural model for early exit of older men in belgium. Empirical Econ 43:379-398

Lehmann H (1993) The effectiveness of the restart programme and enterprise allowance scheme. CEP Discussion Papers dp0139, Centre for Economic Performance, LSE

Looy DV, Kovalenko M, Mortelmans M, Preter HD (2014) Working hours-reduction in the move to full retirement: How does this affect retirement preferences of 50+ individuals in flanders? Technical report, Leuven: Steunpunt Werk en Sociale Economie / Antwerpen: CELLO, Universiteit Antwerpen

López-Novella M (2012) Analysing the impact of eligibility and financial measures aiming at delaying early retirement in belgium: a "difference-in-differences" approach using panel data. Working Paper 14-12, Federal Planning Bureau, Brussels

Machado C, Portela M (2012) Hours of work and retirement behavior. Technical Report 6270, IZA, Institute for the Study of Labor

Maes M (2008) Financial and redistributive impact of reforming the old-age pension system in Belgium. Discussion Papers (ECON - Département des Sciences Economiques) 2008040, Université catholique de Louvain, Département des Sciences Economiques. http://ideas.repec.org/p/ctl/louvec/2008040.html

Mourre G (2006) Did the pattern of aggregate employment growth change in the euro area in the late 1990s? Appl Econ 38(15):1783-1807

Nielsen HB (2004) Cointegration analysis in the presence of outliers. Economet J 7(1):249-271

OECD (2003) Ageing and Employment Policies/Nieillissement Et Politiques de L?emploi: Belgium. OECD, Paris

OECD (2011) Pensions at a glance 2011. OECD Publishing. doi:10.1787/pension_glance-2011-en

Pissarides C (1998) The impact of employment tax cuts on unemployment and wages: The role of unemployment benefits and tax structure. Eur Econ Rev 42:155-183

Spiess C, Schneider A (2003) Interactions between care-giving and paid work hours among european midlife women, 1994-1996. Ageing Soc 23:41-68

Staubli S, Zweimüller J (2013) Does raising the early retirement age increase employment of older workers?. J Publ Econ 108:17-32

Stewart MB, Swaffield JK (1997) Constraints on the desired hours of work of british men. Econ J 107(441):520-35

Vandenberghe V, Waltenberg F, Rigo M (2013) Ageing and employability: Evidence from belgian firm-level data. J Productivity Anal 40:111-136

\section{Submit your manuscript to a SpringerOpen ${ }^{\circ}$ journal and benefit from:}

- Convenient online submission

- Rigorous peer review

- Immediate publication on acceptance

- Open access: articles freely available online

- High visibility within the field

Retaining the copyright to your article

Submit your next manuscript at $\gg$ springeropen.com 